\title{
Ciclo do Petróleo e Desenvolvimento Socioeconômico no Município de Campos dos Goytacazes - 1999/2014
}

\author{
http://dx.doi.org/10.21527/2237-6453.2019.46.314-332
}

Recebido em: 15/12/2017

Aceito em: 29/8/2018

\author{
José Eduardo Manhães da Silva, ${ }^{1}$ Lia Hasenclever ${ }^{2}$
}

\begin{abstract}
RESUMO
O município de Campos dos Goytacazes, localizado na região Norte do Estado do Rio de Janeiro, destacou-se, até recentemente, como o maior receptor de rendas oriundas de royalties e participações especiais do país. O objetivo deste artigo é observar a contribuição do ciclo expansivo da indústria petrolífera na Bacia de Campos, no sentido de superar o subdesenvolvimento local e a promoção do desenvolvimento socioeconômico. A metodologia analisa indicadores socieconômicos do município de Campos dos Goytacazes, no período 1999/2014, comparados aos municípios de Macaé e Niterói, e complementa essa análise por pesquisa na literatura científica sobre o tema. Conclui-se que, apesar do virtuoso ciclo do petróleo e das generosas receitas de royalties e participações especiais auferidos pelo município, constata-se que o subdesenvolvimento não só persiste, mas também se reproduz por conta da deterioração institucional.
\end{abstract}

Palavras-chave: Subdesenvolvimento. Petróleo e gás. Royalties. Campos dos Goytacazes.

OIL CYCLE AND SOCIOECONOMIC DEVELOPMENT

IN THE MUNICIPALITY OF CAMPOS DOS GOYTACAZES - 1999/2014

\section{ABSTRACT}

Campos dos Goytacazes, county located in the north region of the state of Rio de Janeiro, until recently, has been the greatest receiver of royalties and special participations in the country. The objective of this article is to observe the contribution of the expansive cycle of the oil industry in the Campos Basin, in order to overcome local underdevelopment and to promote the socioeconomic development. The methodology analize the socioeconomic indicators of Campos dos Goytacazes in the period 1999/2014, compared to the municipalities Macaé and Niterói, and complemented this analize by research in the scientific literature about the subject. Concludes that, in despite the virtuous cycle of oil and the generous revenues from royalties and special participations shown by the county, it's observed that underdevelopment not only persists, but also increases due to institutional deterioration.

Keywords: Underdevelopment. Oil and gas. Royalties. Campos dos Goytacazes.

\footnotetext{
${ }^{1}$ Mestre em Economia Empresarial pela Universidade Candido Mendes (Ucam). Aluno de Doutorado em Planejamento Regional e Gestão de Cidades da Universidade Candido Mendes (Ucam), Campos dos Goytacazes. Professor da Universidade Federal Fluminense (UFF). jedums@ hotmail.com

${ }^{2}$ Doutora em Engenharia de Produção pela Universidade Federal do Rio de Janeiro (UFRJ). Professora da Universidade Federal do Rio de Janeiro. Professora do Programa de Pós-Graduação em Planejamento Regional e Gestão de Cidades da Universidade Candido Mendes (Ucam), Campos dos Goytacazes. lia@ie.ufrj.br
} 
Campos dos Goytacazes está inserido no norte do Estado do Rio de Janeiro - ERJ que que é composto por 92 municípios. É o maior em extensão territorial do Estado, com $4.032 \mathrm{Km}^{2}$, e considerado um município de porte médio, com população estimada de 487.186 habitantes (2016), segundo o Instituto Brasileiro de Geografia e Estatística IBGE.

Historicamente, o atual município de Campos dos Goytacazes galgou crescente importância no cenário econômico regional, nacional e internacional. Ao longo do século 19 e primeira metade do século 20, Campos dos Goytacazes vivenciou dois ciclos expansivos baseados na produção sucroalcooleira, tendo ostentado no final do século 19 a posição de município com maior produção açucareira do país. Ao final do século 20 e início do século 21, um terceiro ciclo expansivo se apresentou para Campos dos Goytacazes e demais municípios do norte fluminense. O recente ciclo expansivo baseia-se nos investimentos da indústria petrolífera, tendo em vista a exploração e produção de petróleo e gás - P\&G - na Bacia de Campos.

Este novo ciclo, agora fundamentado em atividades industriais e de serviços ligados à exploração e produção de P\&G, caracteriza-se por vultosos investimentos em infraestrutura produtiva offshore, em expressivos dispêndios com atividades de pesquisa e desenvolvimento (P\&D) e pesados gastos na contratação de serviços ligados à indústria. Além disso, entre as externalidades positivas da produção petrolífera no norte fluminense, que respondeu em 2014, segundo a Agência Nacional de Petróleo - ANP - por $68,4 \%$ da produção de óleo e $45,3 \%$ da produção de gás natural do país, estão as receitas de royalties e participações especiais auferidas pelos municípios no entorno da Bacia de Campos, com destaque para o município de Campos dos Goytacazes, que liderou por muitos anos o ranking de maior receptor de royalties do país.

O objetivo deste artigo é analisar a dinâmica socioeconômica de Campos dos Goytacazes, no período de 1999 a 2014, tendo em vista os impactos da produção de P\&G em variáveis econômicas e sociais selecionadas. Busca-se avaliar a contribuição do ciclo expansivo de P\&G como evento potencialmente capaz de viabilizar a reversão da histórica condição de subdesenvolvimento da localidade de Campos dos Goytacazes, visto que sua efetividade deveria ser capaz de trazer benefícios para a sociedade local traduzidos em indicadores socioeconômicos.

Trabalha-se com a hipótese de que o ciclo expansivo do P\&G - apesar do extraordinário potencial produtivo e tecnológico - não produziu, até então, os efeitos esperados para viabilizar as transformações estruturais e institucionais necessárias à superação do subdesenvolvimento do município de Campos dos Goytacazes. No período de análise é possível observar, de forma consistente, os efeitos provenientes dos investimentos e mudanças estruturais e institucionais decorrentes do ciclo produtivo de $P \& G$ em Campos dos Goytacazes e na região norte fluminense, especialmente a partir da Lei no 9.478, de 6 de agosto de 1997, conhecida como Lei do Petróleo, que flexíbiliza o monopólio das atividades de extração e produção, até então exercidas pela Petrobras.

Optou-se por este período devido à limitação de dados oficiais em um espectro temporal mais dilatado para a realização da pesquisa. Do ponto de vista metodológico, utiliza-se o método de análise comparada com outros municípios do ERJ, a saber: Macaé e Niterói. Os dados socioeconômicos foram coletados nos sites dos seguintes órgãos: Cadastro Geral de Empregados e Desempregados - Caged; Programa das Nações 
Unidas para o Desenvolvimento - Pnud; Agência Nacional de Petróleo - ANP; Instituto Brasileiro de Geografia e Estatística - IBGE, e Instituto de Pesquisa Econômica Aplicada - Ipea. A partir desses dados foram construídos os indicadores apresentados no Quadro 1 e suas fontes.

Quadro 1 - Indicadores, variáveis, cálculo e suas fontes

\begin{tabular}{|c|c|c|c|c|}
\hline Indicadores & Variáveis & Ano/Período & Cálculo & Fontes \\
\hline PIB Setorial & PIB e IPCA & $\begin{array}{l}\text { Atualização com } \\
\text { ano-base } 2014\end{array}$ & $\frac{\text { PIB }}{\text { IPCA Acum. }} \times 1.000$ & IBGE \\
\hline \multirow{3}{*}{$\begin{array}{l}\text { Emprego e } \\
\text { Renda }\end{array}$} & $\begin{array}{l}\text { Remuneração média dos } \\
\text { empregos formais }\end{array}$ & Ano 2014 & $\frac{\sum \text { Salário do Setor }}{\text { Total Trab.Setor }}$ & \multirow{2}{*}{ Rais } \\
\hline & $\begin{array}{l}\text { Evolução dos Empregos } \\
\text { Formais }\end{array}$ & 1999 e 2004 & --- & \\
\hline & $\begin{array}{l}\text { Faixa de remuneração } \\
\text { média por setor }\end{array}$ & 2014 & --- & IBGE \\
\hline $\begin{array}{l}\text { Arrecadação } \\
\text { Municipal }\end{array}$ & $\begin{array}{l}\text { Participação relativa das } \\
\text { receitas municipais }\end{array}$ & 2013 & $\begin{array}{l}\frac{\text { Tríbuto/Taxa }}{\text { Total }} \\
\text { Tríbuto/Taxa }\end{array}$ & Finbra/STN \\
\hline Educação & $\begin{array}{l}\text { № estabelecimentos de } \\
\text { Ensino Médio }\end{array}$ & 2005 a 2015 & --- & $\begin{array}{l}\text { IBGE } \\
\text { Cidades }\end{array}$ \\
\hline Pobreza & Taxa de pobreza & 1991 e 2000 & --- & Ipea \\
\hline Saúde & Investimento per capita & 2004 a 2014 & $\frac{\text { Inv.Saúde/IPCA }}{\text { População }}$ & Siops \\
\hline IDHM & Saúde, educação e renda & $1991 / 2000 / 2010$ & $\begin{array}{c}-- \\
--\end{array}$ & Pnud \\
\hline
\end{tabular}

Fonte: Elaboração própria.

A escolha para comparação com os municípios de Macaé e Niterói deve-se ao fato de o primeiro possuir um protagonismo semelhante quanto ao contexto da produção extrativa de $P \& G$, além da proximidade territorial com o município de Campos dos Goytacazes. Já a comparação com Niterói deve-se à semelhança quanto à densidade populacional de Campos dos Goytacazes, apesar de Niterói possuir uma economia mais desenvolvida.

Além desta introdução, o artigo é assim desenvolvido: inicialmente apresentam-se os referenciais teórico e metodológico, com a abordagem estruturalista de Celso Furtado, pela ótica analítica de Sachs e Warner (1995); na sequência realizam-se análises econômicas e sociais do município de Campos dos Goytacazes, com destaque para a evolução respectivamente do PIB setorial do município e de indicadores que refletem sua economia; a evolução de indicadores de pobreza e indigência, encerrando-se a seção com informações sintéticas sobre o desenvolvimento por meio dos indicadores do Programa das Nações Unidas para o Desenvolvimento - Pnud. A última seção é destinada às considerações finais do trabalho.

\section{DESENVOLVIMENTO E RECURSOS NATURAIS ABUNDANTES}

Há um consenso de que o crescimento econômico decorre do aumento da produtividade derivada da incorporação dos fatores de produção ao processo de expansão da produção, tais como capital, trabalho, tecnologia e capacidade empresarial, com tal crescimento sendo medido pelo Produto Interno Bruto (PIB). Por sua vez, até meados 
dos anos 80, o PIB per capita figurava como o principal indicador do nível de bem-estar econômico e social de países e regiões. Nessa perspectiva, percebia-se o desenvolvimento econômico como resultado da expansão econômica e do aumento da produtividade. Não considerava-se, então, os indicadores sociais, por exemplo, acesso à saúde, à educação e o nível de pobreza de uma dada população. Já no final dos anos 80 e início de 90, sobretudo a partir de contribuições seminais do economista indiano Amartya $\operatorname{Sen}^{3}$ (2000), a noção de desenvolvimento passaria a incluir a dimensão social. Assim, além do PIB per capita, indicadores como o Índice de Desenvolvimento Humano (IDH) passariam a ser utilizados para dimensionar o desenvolvimento econômico e social de países e regiões.

Já os estudos sobre desenvolvimento econômico realizados por autores como Ragnar Nurkse (1957), Gunnar Myrdal (1957), Albert Hirschman (1961) e Celso Furtado (2009), distinguem regiões economicamente subdesenvolvidas das economicamente desenvolvidas. Estes estudos foram influenciados especialmente pela Teoria Geral de Keynes (1996), tendo em vista a noção de que o crescimento econômico ocorre em uma perspectiva de desequilíbrio sistemático, em contraposição à noção do crescimento econômico equilibrado, como proposto pela escola neoclássica. A perspectiva de se manter a economia crescendo a pleno emprego dos fatores de produção, por meio de políticas anticíclicas, foi a tônica dos police-makers a partir de 1945. A grande lição percebida em fins dos anos 70, contudo, foi que o crescimento econômico, decorrente do aumento da produtividade, pode ocorrer de forma muito concentrada, sem que parcelas consideráveis da população tenham acesso ou se beneficiem de seus frutos, ${ }^{4}$ a despeito do que era defendido pelo pensamento cepalino ${ }^{5}$ nos anos 50 a 70.

Em outra perspectiva, observam-se teorias do crescimento econômico que privilegiam um enfoque mais mesoeconômico e que dão lugar à discussão da importância dos espaços local/regional no processo de desenvolvimento. Neste sentido, destacam-se abordagens que ressaltam a importância das economias de aglomeração, em particular aglomerações industriais, ${ }^{6}$ como elemento-chave na explicação do crescimento econômico.

\footnotetext{
${ }^{3}$ Nesse sentido, Sen enuncia o novo conceito de desenvolvimento: "O desenvolvimento consiste na eliminação de privações de liberdade que limitam as escolhas e as oportunidades das pessoas de exercer ponderadamente sua condição de agente" (SEN, 2000, p. 10).

${ }^{4}$ Segundo Furtado (2006, p. 25), um expoente do pensamento cepalino, "O desenvolvimento não é apenas um processo de acumulação, de aumento de produtividade macroeconômica, mas principalmente o caminho de acesso às formas sociais mais aptas a estimular a criatividade humana e responder às aspirações da coletividade. Dispor de recursos para investir está longe de ser condição suficiente para preparar um futuro melhor para a massa da população. Mas quando o projeto social prioriza e efetiva a melhoria das condições de vida desta população, o crescimento se metamorfoseia em desenvolvimento".

5 "O desenvolvimento econômico é um fenômeno com uma nítida dimensão histórica. Cada economia que se desenvolve enfrenta uma série de problemas que Ihe são específicos, se bem que muitos deles sejam comuns a outras economias contemporâneas" (FURTADO, 2009, p. 11)

${ }^{6}$ Alfred Marshall, em sua obra "Princípios de Economia" (1996), é considerado o precursor desta abordagem, consubstanciada na definição dos conceitos que definem o chamado "Distrito Industrial Marshalliano".
} 
Complementarmente, o arcabouço estruturalista-furtadiano é de suma importância para a compreensão da dinâmica socioeconômica de regiões e localidades de baixo desenvolvimento ou periféricas ${ }^{7}$ que estabelecem uma relação centro-periferia no contexto nacional e, em alguns casos, internacional, como é o caso de Campos dos Goytacazes. Na perspectiva furtadiana, as relações de subordinação, no esquema centro-periferia, que explicam o subdesenvolvimento de regiões periféricas ou atrasadas, passam inexoravelmente pelas questões de sua "formação socioeconômica", que envolve questões estruturais e institucionais em uma perspectiva histórica (FURTADO, 2009).

A região norte fluminense e, em particular, o município de Campos dos Goytacazes, figuram como os maiores produtores de $P \& G$ do país $(60 \%)$. O norte fluminense e Campos dos Goytacazes figuram ainda entre os maiores produtores mundiais de P\&G. Mais recentemente, alguns teóricos investigaram a relação entre recursos naturais abundantes e desenvolvimento socioeconômico. ${ }^{8}$ Em um contexto de abundância destes recursos naturais, cumpre investigar como tal riqueza tende a contribuir para o crescimento e desenvolvimento do município e da região norte fluminense.

Nesta linha de raciocínio, o recorte analítico construído por Sachs e Warner (1995) aponta para uma relação inversa entre desenvolvimento econômico e abundância de recursos naturais. Após terem analisado 95 diferentes países, com elevada e reduzida dotação de recursos naturais, os autores chegaram ao seguinte paradoxo: países com recursos naturais abundantes apresentam, em geral, taxas relativamente baixas de crescimento econômico devido à denominada doença holandes ${ }^{9}{ }^{9}$ expressão que passou a designar os resultados negativos derivados da valorização cambial sobre os setores produtivos exportadores e, consequentemente, sobre o desenvolvimento econômico.

Sachs e Warner (1995) dividem a economia em três setores: o setor de comércio do recurso natural, um setor industrial de transformação (não vinculado ao de recurso natural) e um setor não comercial. Nesse contexto, quanto mais recursos naturais existirem, maior será a demanda por bens não industriais e, consequentemente, menor será a alocação de trabalho e do capital no setor industrial de transformação. Em decorrência desse cenário, quando os recursos naturais são abundantes, a produção é mais concentrada em recursos naturais do que em produtos industrializados. Assim, capital e trabalho, que de outra maneira poderiam ser empregados na indústria de transformação, são alocados no setor de serviços e em atividades relacionadas à produção do recurso natural.

Além disso, nos países ricos em recursos naturais o ensino voltado para a formação de profissionais que atuem na atividade extrativa do recurso abundante debilitará a formação de profissionais de outras áreas por deficiência de demanda de formação. Com isso, um círculo vicioso se forma, visto que a evasão reduzirá a quantidade e a capacidade dos docentes relacionados ao ensino e formação de outras áreas produti-

\footnotetext{
Regiões com baixo desenvolvimento ou periféricas apresentam as seguintes características: concentração de renda em uma elite ligada à atividade extrativista; baixa heterogeneidade produtiva; subemprego e baixa renda; mão de obra abundante e de baixa qualificação, baixo nível de poupança.

${ }^{8}$ Ver CAVALIERI; TORRES; HASENCLEVER (2013).

${ }^{9}$ Esta expressão deriva da experiência holandesa, que após a descoberta de jazidas de gás natural em 1960, sofreu com a apreciação cambial devido aos elevados níveis de exportação desse recurso natural, o que prejudicou a competitividade dos setores produtivos exportadores.
} 
vas, impactando e tornando mais deficiente a educação das gerações seguintes, assim como concentrada em uma única área. ${ }^{10}$ Sachs e Warner (1995) também explicitam as questões institucionais, notadamente aspectos burocráticos e éticos, como fatores que podem impactar negativamente o crescimento econômico em países ricos em recursos naturais. Complementando, Sachs e Warner (1995) apresentam um argumento no qual afirmam que os governos que controlam os rendimentos dos recursos naturais tendem a desperdiçar esses rendimentos por meio do consumo desnecessário ou impróprio.

Na perspectiva contemporânea, o conceito de desenvolvimento passa a englobar problemas sociais, envolvendo especialmente a questão da pobreza e indigência com restrição às liberdades individuais propugnadas pela escola neoclássica. E esse entendimento tem aumentado na contemporaneidade, tornando possível sua compreensão e dimensionamento por intermédio de indicadores, que, por sua vez, derivam em controvérsias devido a limitações em suas concepções e avaliações. A pobreza, como exemplo, possui características multidimensionais que exigem a existência de um indicador que tenha uma correspondente abordagem multidimensional e que leve em consideração a situação de como o indivíduo percebe sua própria situação na sociedade.

Assim sendo, o arcabouço teórico no que respeita ao desenvolvimento de uma região permeia diversas dimensões, inclusive a análise de desenvolvimento baseada na produção de P\&G. Nesse contexto o recorte analítico de Sachs e Warner (1995) aponta para as adversidades socioeconômicas provenientes da abundância desses recursos naturais. Na seção a seguir apresentam-se os indicadores socioeconômicos do município de Campos dos Goytacazes, comparados com os municípios de Macaé e Niteroi.

\section{ANÁLISE SOCIOECONÔMICA COMPARADA DO MUNICÍPIO DE CAMPOS DOS GOYTACAZES}

Os dois ciclos expansivos anteriores à atividade petrolífera, como mencionado anteriormente, eram fundamentados na produção sucroalcooleira e não resultaram em desenvolvimento socioeconômico de Campos dos Goytacazes (ROSENDO; CARVALHO, 2004), no entanto, baseando-se nos investimentos petrolíferos e em suas potenciais externalidades, entre elas os royalties petrolíferos, o ciclo expansivo do petróleo apresentou-se com extraordinário potencial para promover mudanças estruturais e institucionais em Campos dos Goytacazes e região norte fluminense, especialmente por conta do alto conteúdo tecnológico da indústria.

Assim, respaldando-se nessa hipótese, esta seção analisa alguns indicadores econômicos e sociais, a partir do ano de 1999 até 2014. Nesse período o monopólio das atividades de exploração e produção de petróleo, até então exercido pela Petrobras, já havia sido extinto pela Lei no 9.478/97, conhecida como Lei do Petróleo.

\footnotetext{
${ }^{10}$ Sachs e Warner descrevem que: "In an overlapping generations model, a resource-rich economy can arrive at a stationary state in which each generation chooses to forgo education, and to work directly in the nontradeable sector, since the price and hence market wage in that sector is above the marginal value product of labor in manufacturing. In a resource-poor economy, by contrast, workers will move into manufactures, and will have the incentive to invest in education, since higher-skilled manufacturing workers earn a premium over uneducated workers. The education process will produce not only skilled workers, but also more skilled teachers in the next generation" (SACHS; WARNER, 1995, p. 8).
} 
A Tabela 1 apresenta a evolução do PIB de Campos dos Goytacazes para os anos de 1999 e 2014. Considerando-se o PIB deflacionado pelo IPCA, ${ }^{11}$ constata-se que o incremento real no período foi da ordem de 256,2\%, abaixo do município de Macaé (272,5\%), porém maior do que a variação para o município de Niterói $(88,5 \%)$ e do ERJ, no qual verificou-se um aumento médio anual de $80 \%$.

Tabela 1 - PIB do ERJ e municípios selecionados - 1999 e 2014

\begin{tabular}{l|r|r|r}
\hline \multicolumn{1}{c|}{ Munícipio } & \multicolumn{1}{c|}{1999} & \multicolumn{1}{c|}{2014} & $\Delta \%$ média anual \\
Campos dos Goytacazes & 1.298 .366 & 54.516 .768 & 256,2 \\
Macaé & 443.591 & 19.782 .975 & 272,5 \\
Niterói & 1.520 .362 & 23.045 .367 & 88,5 \\
\hline ERJ & 45.697 .993 & 630.652 .048 & 80,0 \\
\hline
\end{tabular}

Fonte: IBGE, 2017. Preços constantes IPCA - base 2014 (x 1.000). Elaboração própria.

O comportamento dos setores econômicos dos municípios analisados apresentaram algumas variações em relação as suas participações percentuais na composição do PIB no período de análise.

O setor agropecuário apresentou diminuição na participação do PIB em todos os municípios, assim como no ERJ. Tanto em Campos dos Goytacazes, com crescimento de 15,8 pontos percentuais (pp), entre 1999 e 2014, como em Niterói (19 pp) e no ERJ (7,5 $\mathrm{pp})$, observa-se um crescimento significativo no setor produtivo industrial. Já em Macaé esse aumento foi menos expressivo, atingindo 2,5 pp. Esse comportamento foi reflexo direto da produção mineral extrativa de $P \& G$. O setor de serviços também apresentou redução relativa em todas as esferas analisadas, porém o comportamento que a princípio se evidencia ao contexto é o aumento da participação da administração pública, conforme Tabela 2.

Tabela 2 - Participação \% das atividades econômicas no PIB - 1999 e 2014

\begin{tabular}{|l|r|r|r|r|r|r|r|r|}
\hline $\begin{array}{c}\text { PIB por } \\
\text { atividade } \\
\text { econômica }\end{array}$ & \multicolumn{2}{|c|}{$\begin{array}{c}\text { Campos dos } \\
\text { Goytacazes }\end{array}$} & \multicolumn{2}{|c|}{ Macaé } & \multicolumn{2}{c|}{ Niterói } & \multicolumn{2}{c|}{ Estado RJ } \\
\hline & 1999 & 2014 & 1999 & 2014 & 1999 & 2014 & 1999 & 2014 \\
\hline Adm.Pública & 3,4 & 7,6 & 8,4 & 25,8 & 7,1 & 21,7 & 13,7 & 29,0 \\
\hline Agropecuária & 2,0 & 0,3 & 1,2 & 0,2 & 0,1 & 0,15 & 0,06 & 0,4 \\
\hline Indústria & 48,8 & 64,6 & 35,5 & 38,1 & 11,2 & 30,2 & 18,1 & 25,6 \\
\hline Serviços & 45,8 & 27,6 & 54,8 & 35,9 & 81,6 & 48,0 & 67,6 & 45,0 \\
\hline Total & 100,0 & 100,0 & 100,0 & 100,0 & 100,0 & 100,0 & 100,0 & $100,0 \%$ \\
\hline
\end{tabular}

Fonte: IBGE... 2017. Elaboração própria.

${ }^{11}$ Índice de correção oficial do governo brasileiro. 
O acréscimo na participação relativa da administração pública em Campos dos Goytacazes aparentemente foi menos expressivo (4,1 pp), mas cabe ressaltar que, devido à significativa participação do setor industrial de extração mineral, toda a composição relativa das demais atividades produtivas do município tendem a ser minoradas.

A limitada abrangência das informações, por parte dos órgãos estatísticos, quanto à composição podutiva do setor industrial, no que se refere à divisão do PIB entre indústria extrativa mineral e indústria de transformação, prejudica a análise quanto ao crescimento ou deteriorização da indústria de transformação. Nesse contexto, passou então a ser utilizada a mensuração do PIB decorrente da metodologia do IBGE que, desde 1998, com base nas Contas Regionais do Brasil, constrói as estimativas do PIB dos municípios agrupando as atividades econômicas nos setores primário, secundário e terciário. Essa metodologia, porém, não permite, conforme já mencionado, uma análise detalhada e distinta da performance de cada atividade produtiva econômica dos municípios.

Sachs e Warner ${ }^{12}$ (1995), com base nos resultados de sua pesquisa, indicam que, devido à existência e atuação do setor extrativo mineral abundante, os demais setores, inclusive de transformação, apresentam um crescimento menor. Assim, pode-se supor que, diante dos investimentos significativos na indústria extrativa e da ausência de atividades de refino no município de Campos, a atividade da indústria de transformação tenha se reduzido ou não tenha crescido tanto.

No período analisado percebeu-se um expressivo aumento de produção, mensurada pelo PIB. Cumulativamente, porém, Campos dos Goytacazes destaca-se como o município com a segunda maior participação $(7,8 \%)$ do PIB do ERJ, ficando atrás somente do município do Rio de Janeiro (46,5\%). Niterói está na quarta posição $(3,1 \%)$ e Macaé na quinta colocação (2,8\%). Na Figura 1, verifica-se o montante acumulado do PIB no período analisado.

Figura 1- PIB municipal acumulado 1999/2014 - valores constantes x1.000 - IPCA (base 2014).

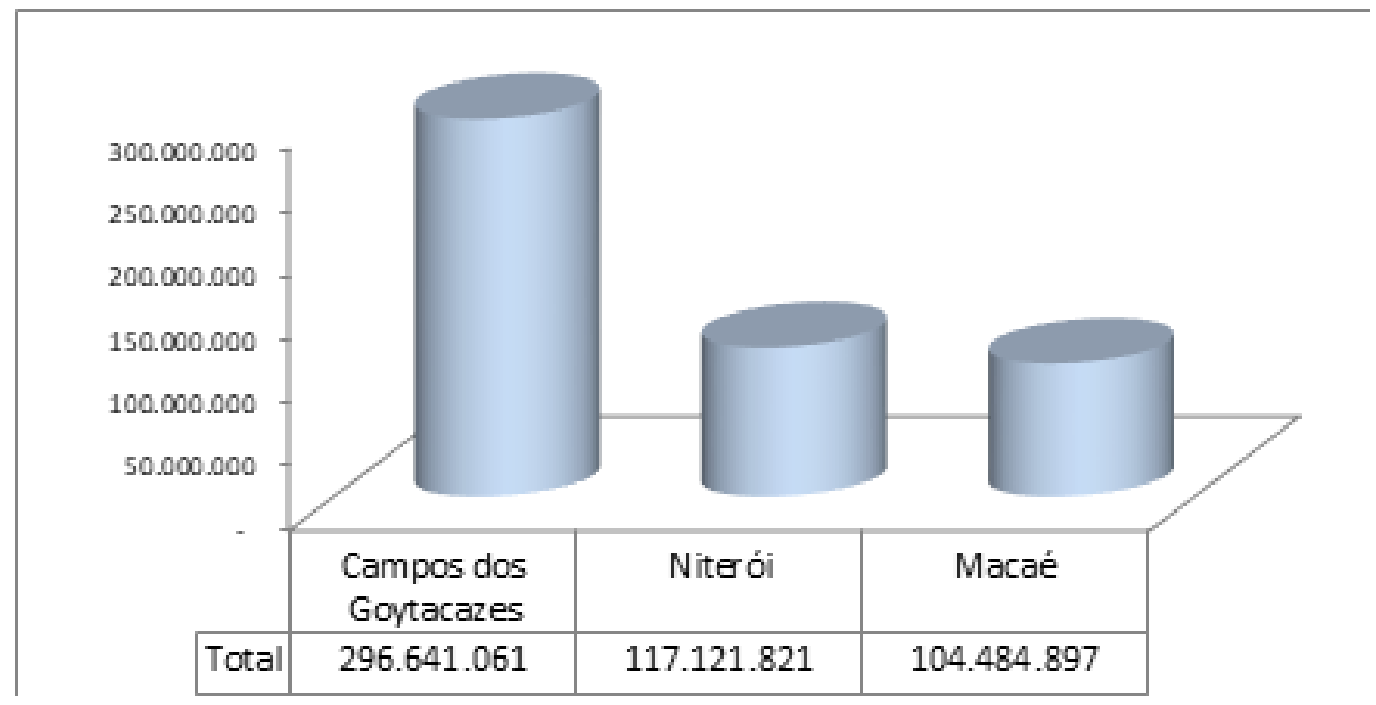

Fonte: IBGE, 2017. Elaboração própria.

\footnotetext{
$\overline{12 " A ~ r e g r e s s i o n ~ o f ~ g r o w t h ~ o f ~ n o n-r e s o u r c e ~ G D P ~ o n ~ n a t u r a l ~ r e s o u r c e ~ i n t e n s i t y ~ a n d ~ a ~ n u m b e r ~ o f ~ o t h e r ~ v a r i a b l e s ~(. . .) . ~}$ The results indicate that growth in real value added in manufacturing and services was indeed slower in natural-resource-intensive economies." (SACHS; WARNER, 1995, p. 17).
} 
Outro aspecto que dificulta a análise é que a metodologia utilizada para mensurar o valor da produção dos campos petrolíferos no PIB dos munícipios é um indicador econômico que pode não estar transmitindo um entendimentos concreto da realidade. Esse aspecto decorre do fato de que a metodologia utilizada pelo IBGE se dá com base nas premissas de alocação produtiva da Agência Nacional do Petróleo - ANP - por meio da qual a contabilização da produção de $P \& G$ é realizada considerando-se o município confrontante ao poço, sem levar em conta se a riqueza é realmente canalizada para o município ou não, conforme definido pelo $\mathrm{IBGE}^{13} \mathrm{em}$ seu relatório metodológico.

Essa alocação, que podemos considerar fora da realidade, resulta em distorções, pois, excetuando-se os recursos dos royaties e das participações especiais, a riqueza produzida não é apropriada plenamente pelo município, mas somente contabilizada como se assim o fosse, o que dá margens ao entendimento equivocado de que o município e seus residentes se beneficiam da riqueza total proveniente da extração do petróleo.

A alocação contábil da riqueza mineral extraída da Bacia de Campos, por parte do IBGE, não exprime a real evolução econômica dos munícipios no entorno da Bacia. Com isso, tanto o PIB como o PIB per capita mensurados pelo IBGE podem ser considerados, apesar de sua composição seguir um critério, superdimensionados e distorcidos do ponto de vista da real geração de riqueza para os municípios. Assim sendo, a análise do PIB municipal definido pelo IBGE para municípios considerados produtores de petróleo deve ser vista com cautela. Dessa forma, a contabilização da riqueza oriunda da extração mineral, cuja rede de produção extrapola as fronteiras municipais, como o caso do petróleo da Bacia de Campos, poderia ter um tratamento de alocação diferenciado (CRUZ, 2004).

Nesse contexto, o município de Campos dos Goytacazes, assim como os demais municípios da região, só se beneficiam do montante financeiro a eles repassados a título de royalties e participações especiais, sem que haja a inserção de atividades produtivas geradoras de transbordamentos e externalidades que proporcionem instrumentos viabilizadores de desenvolvimento socioeconômico local.

Conforme Cunha (2009), do universo que contempla a população economicamente ativa de Campos dos Goytacazes, verifica-se que parte dessa população é composta por indivíduos qualificados que, devido à oferta de empregos na indústria de $P \& G$, acabam por atuar em Macaé. Outra parcela, com reduzido nível de qualificação, atua no comércio e na prestação de serviços locais, em decorrência das oportunidades oriundas do ciclo econômico de $P \& G$ e outra parte encontra-se desempregada ou trabalhando informalmente, pois não possuem qualificação.

Como é possível observar no Gráfico 1, a remuneração média dos trabalhadores, segundo a Relação Anual de Informações Sociais - Rais - do município de Campos dos Goytacazes está bem abaixo das remunerações médias de outros municípios do ERJ, como Macaé, em que os empregos estão diretamente relacionados às atividades de serviços ligados à exploração de $P \& G$, por conta deste município ter se tornado a base

\footnotetext{
13"Em relação ao petróleo e gás natural, o rateio entre os municípios é feito pela estrutura construída sobre a quantidade produzida de petróleo e gás natural, no mar e em terra, de cada município. Essa informação é fornecida pela Agência Nacional do Petróleo, Gás Natural e Biocombustiveis - ANP. A regionalização da produção por município necessita do estabelecimento de premissas que norteiem a sua correta alocação" (IBGE - Relatórios Metodológicos - PIB dos Munícipios, 2010, p. 19).
} 
operacional destas atividades na Bacia de Campos. A remuneração média de Campos dos Goytacazes equivale a 40,7\% da remuneração média de Macaé, que é fortemente influenciada pela indústria petrolífera. Esse aspecto deriva do fato de Campos dos Goytacazes ser um município-dormitório e fornecedor de mão de obra qualificada para a exploração e produção do $P \& G$ na Bacia de Campos.

Gráfico 1 - Remuneração Média dos Empregos Formais - 2014

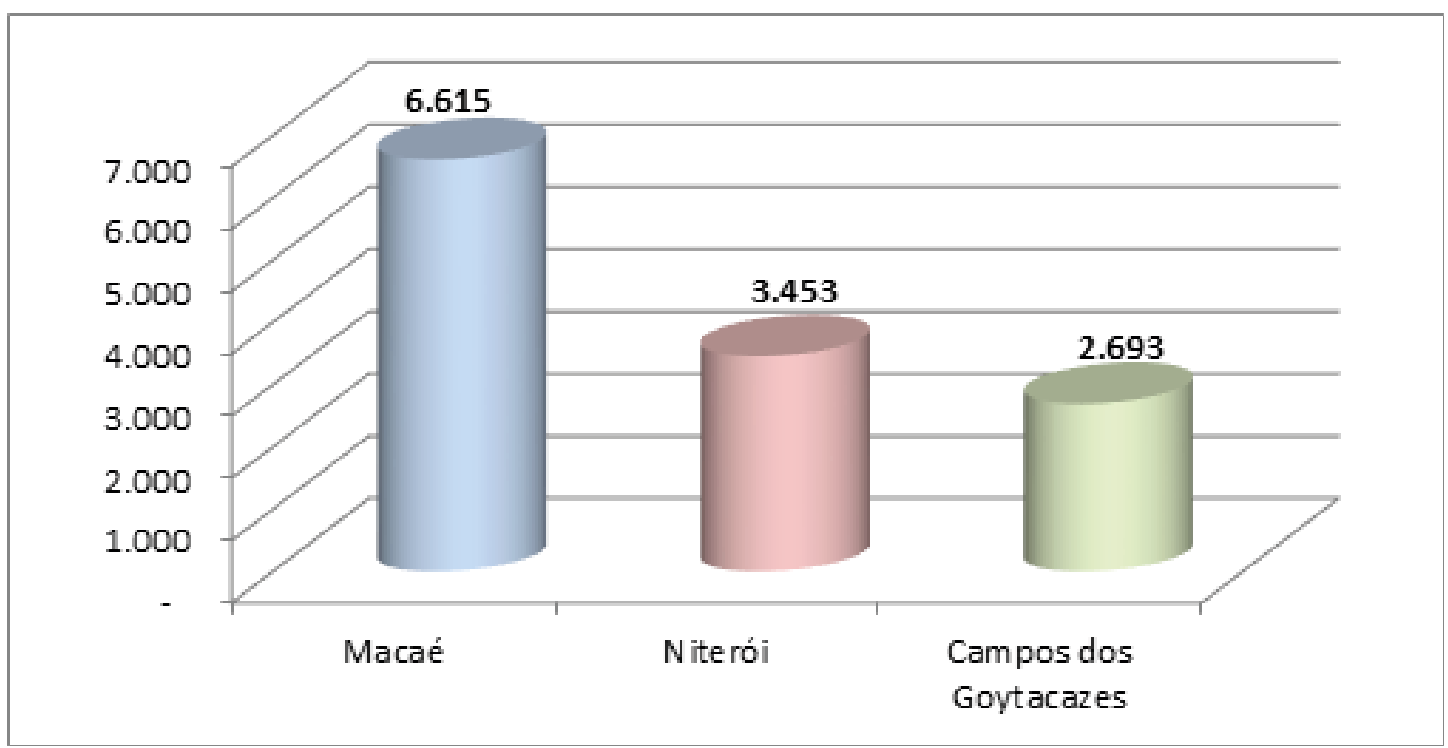

Fonte: RAIS (2007). Elaboração própria.

O Ministério do Trabalho e Emprego - MTE - considera, para fins de alocação de vínculo empregatício, o município e a Unidade Federativa onde a empresa está sediada/ registrada, segundo a Rais (RAIS, 2007). Assim, neste caso específico, a mão de obra vinculada à extração petrolífera na Bacia de Campos é definida como sendo localizada em Macaé - base operacional da indústria petrolífera, na qual se concentram os empregos ligados à referida atividade. Isso implica a apropriação inadequada dos salários dos residentes em Campos dos Goytacazes que trabalham em Macaé e assim distorcendo o salário médio dos residentes de ambos os municípios.

Assim sendo, o município de Campos dos Goytacazes, segundo dados do Caged, detém o menor salário médio quando comparado com os municípios de Macaé e Niterói, e possui o 19 maior salário médio (2014) entre todos os 92 municípios do ERJ, sugerindo que a riqueza gerada pela produção de $P \& G$ não esteja beneficiando seus residentes.

Esse contexto também é exposto por Hasenclever, Filho e Piquet (2017), citando pesquisa de Hasenclever (2013), quanto ao nível de educação dos indivíduos na economia de P\&G na Bacia de Campos, refletindo-se, no caso, negativamente na empregabilidade e nível de renda dos trabalhadores de Campos dos Goytacazes, vindo, também, a alinhar-se à proposta de Sachs e Warner (1995) quanto à deficiência na qualificação e impondo-Ihes uma posição desfavorável.

Ao analisarmos o comportamento agregado do emprego formal, segundo Cadastro Geral de Empregados e Desempregados - Caged, em Campos dos Goytacazes, assim como nos municípios de Macaé e Niterói, no período de 1999 até 2014, constatamos 
que o nível desses empregos cresceu significativamente, a saber: Campos dos Goytacazes com um incremento da ordem de 136,7\%, Macaé 371,1\% e Niterói 83,7\%. Em Campos dos Goytacazes destacam-se os setores de Serviços Industriais de Utilidade Pública - Siup (301,8\%) e construção civil (282\%), o que pode estar refletindo na ampliação da infraestrutura do município.

Em Macaé os percentuais de ampliação da mão de obra formal são bastante expressivos, também destacando-se a construção civil $(781,1 \%)$ e Siup $(628,1 \%)$ e assim como supõe-se para Campos dos Goytacazes, esse aumento pode significar esforços para incrementar a infraestrutura já existente no município. Já em Niterói os percentuais de evolução nesses setores são menos expressivos, provavelmente por ser um município que já possui uma economia constituída e ampla, principalmente no setor de serviços. Essa evolução, entretanto, apresenta percentuais significativos no setor de extração mineral $(2.655,7 \%)$ e o decréscimo no setor agropecuário (-52,0\%). A Tabela 3 detalha a evolução dos empregos formais no período 1999 e 2014 em Campos dos Goytacazes, Macaé, e Niterói.

Tabela 3 - Evolução dos empregos formais no período 1999 e 2014 - Categorizado: IBGE Setores

\begin{tabular}{lrrrrrrrrr}
\hline & \multicolumn{3}{c}{ Campos dos Goytacazes } & \multicolumn{3}{c}{ Macaé } & \multicolumn{3}{c}{ Niterói } \\
& 1999 & 2014 & \multicolumn{1}{c}{$\Delta \%$} & 1999 & 2014 & $\Delta \%$ & 1999 & 2014 & $\Delta \%$
\end{tabular}

Fonte: RAIS, 2007. Elaboração própria.

A degeneração da indústria de transformação, como visto, é destacada pela abordagem estruturalista como o fator mais relevante na explicação do subdesenvolvimento de um país ou região e está intimamente relacionada à produção e exportação de produtos primários para o mercado externo. Esta relação pode ser percebida na economia de Campos dos Goytacazes, contribuindo ainda para que haja baixa diversidade produtiva, pouca produtividade e precário desenvolvimento tecnológico.

Sachs e Warner (1995) afirmam que em países e regiões abundantes em recursos naturais ocorre mais intensamente a promoção do emprego nos setores ligados à extração desses recursos naturais em detrimento da indústria de transformação. Pode-se constatar, entretanto, que, nos municípios analisados e no período avaliado a atividade extrativa de $P \& G$, na Bacia de Campos, promoveu transbordamentos nos demais setores econômicos produtivos, pois em todos os municípios analisados o volume de emprego formal cresceu, excetuando-se a atividade agropecuária nos municípios de Campos dos Goytacazes e Niterói, que apresentaram perdas de postos de trabalho formal. 
Outro importante aspecto relacionado aos municípios analisados e que ratifica o entendimento de baixa apropriação de riqueza gerada para os residentes do município de Campos dos Goytacazes diz respeito ao diferencial da média dos salários pagos pelos diferentes setores econômicos. O único setor econômico no qual a média salarial de Campos dos Goytacazes é superior à média salarial dos municípios de Macaé e Niterói é o setor de administração pública, como é possível verificar na Tabela 4.

Tabela 4 - Faixa de remuneração média por setor (IBGE) - 2014 - valores correntes

\begin{tabular}{|c|c|c|c|c|c|}
\hline \multirow{2}{*}{$\begin{array}{c}\text { Setores de atividade } \\
\text { econômica }\end{array}$} & Macaé & $\begin{array}{l}\text { Campos dos } \\
\text { Goytacazes }\end{array}$ & Niterói & \multicolumn{2}{|c|}{$\Delta \%$} \\
\hline & $\mathrm{R} \$$ & $\mathrm{R} \$$ & $\mathrm{R} \$$ & $C G / M a c a e ́$ & CG/Niterói \\
\hline Extrativa Mineral & $13.921,10$ & $1.299,84$ & $11.553,07$ & $-90,7$ & $-88,7$ \\
\hline Indústria de Transf. & $4.179,84$ & $1.482,14$ & $3.185,35$ & $-64,5$ & $-53,5$ \\
\hline S.I.U.P. & $7.883,85$ & $2.400,81$ & $2.809,98$ & $-69,5$ & $-14,6$ \\
\hline Construção Civil & $3.875,18$ & $1.480,31$ & $2.249,71$ & $-61,8$ & $-34,2$ \\
\hline Comércio & $2.072,44$ & $1.321,89$ & $1.436,80$ & $-36,2$ & $-8,0$ \\
\hline Serviços & $3.794,61$ & $2.127,19$ & $2.599,05$ & $-43,9$ & $-18,2$ \\
\hline Adm. Pública & $3.885,48$ & $4.392,73$ & $4.124,22$ & 13,1 & 6,5 \\
\hline Agropecuária & $1.279,16$ & $1.221,94$ & $5.011,59$ & $-4,5$ & $-75,6$ \\
\hline Média & $5.111,46$ & $1.965,86$ & $4.121,22$ & $-61,5$ & $-52,3$ \\
\hline
\end{tabular}

Fonte: RAIS, 2007. Elaboração própria.

A diferença entre as médias das remunerações dos municípios de Campos dos Goytacazes em relação a Macaé equivale a $-61,5 \%$ e a diferença entre as médias das remunerações dos municípios de Campos dos Goytacazes em relação a Niterói é de $-52,3 \%$. Essas diferenças das médias são basicamente explicadas pela remuneração média praticada na indústria extrativa mineral.

A principal fonte de receita orçamentária (Tabela 5) de Campos dos Goytacazes são oriundas das transferências da União (58,5\%) e dos Estados (15,9\%), enquanto que as receitas tributárias derivadas das ações produtivas em seu território contemplam um percentual reduzido $(8,1 \%)$, o que significa um vultoso risco para a gestão pública municipal. Percebe-se, nos municípios de Niterói e Macaé, uma melhor distribuição entre os montantes oriundos da receita tributária, transferências da União e de Estados.

A composição de receitas orçamentárias do município de Campos dos Goytacazes, como a observada no exercício de 2013 (Tabela 5), constitui-se uma séria fragilidade, visto que a ocorrência de uma crise ou colapso na economia nacional ou global, conforme já ocorrido recentemente (2008), poderá resultar em sério agravamento na obtenção de recursos para investimento e manutenção de ações voltadas à sociedade.

Tabela 5 - Participação relativa das receitas municipais:

Campos dos Goytacazes, Macaé e Niterói - 2013.

\begin{tabular}{lrrr}
\hline Receitas & Campos dos & Macaé & \multicolumn{1}{c}{ Niterói } \\
Receitas Correntes & 100,00 & 100,00 & 100,00 \\
Receita Tributária & 8,10 & 30,00 & 39,00 \\
IPTU & 1,00 & 1,30 & 13,60 \\
IRPQN & 1,90 & 3,30 & 2,40
\end{tabular}




\begin{tabular}{lrrr} 
ITBI & 0,70 & 1,00 & 6,20 \\
ISS & 4,00 & 24,00 & 14,50 \\
Taxas & 0,50 & 0,50 & 2,20 \\
Contribuições & 6,60 & 7,90 & 5,80 \\
\hline Transf. União & 58,50 & 29,80 & 22,50 \\
FPM & 1,80 & 2,70 & 3,40 \\
Royalties & 50,30 & 24,20 & 8,10 \\
SUS & 4,50 & 1,90 & 9,90 \\
Outras & 1,70 & 1,10 & 1,10 \\
Transf. Estados & 15,90 & 25,00 & 22,60 \\
ICMS & 13,40 & 21,80 & 16,50 \\
IPVA & 1,00 & 1,40 & 4,90 \\
IPI & 0,30 & 0,50 & 0,40 \\
Outras & 1,20 & 1,30 & 0,80 \\
FUNDEB & 9,50 & 4,50 & 4,90 \\
\hline Outras Receitas & 1,40 & 2,80 & 5,20 \\
\hline
\end{tabular}

Fonte: FINBRA/STN - Situação Fiscal dos Munícipios. Elaboração própria.

Sachs e Warner (1995), em seu recorte analítico, atribuem aos governantes de regiões detentoras de abundantes riquezas naturais a característica de negligência arrecadadora, em virtude do significativo volume de recursos que ingressam nos cofres públicos devido ao recebimento de compensações pela extração do minério abundante, contexto percebido no município de Campos dos Goytacazes, conforme disposto na Tabela 5 .

Para dar conta da dimensão que compreende o desenvolvimento, e como expresso anteriormente, faz-se necessária a análise de outros indicadores, índices ou parâmetros sociais, tais como educação, pobreza e saúde.

No contexto da educação, o analfabetismo ainda apresenta-se como um problema a ser superado no Brasil, em suas regiões e municípios e devido a isso mostra-se ainda como um dos principais fatores inibidores do desenvolvimento socioeconômico, principalmente quando consideramos a importância da educação na obtenção de emprego e renda do indivíduo.

Observando-se os dados do Programa das Nações Unidas para o Desenvolvimento - Pnud - verificamos uma redução do nível de analfabetos em Campos dos Goytacazes, passando da ordem de $15,5 \%$ (1991) de sua população para $10,1 \%$ (2000), tendo sido o município, entre os analisados, o que mais reduziu o nível de analfabetismo. Macaé reduziu de $12,6 \%$ para 7,9\% e Niterói passou de 5,4\% para 3,6\%. O nível de analfabetismo em Campos dos Goytacazes, todavia, ainda é bem elevado e superior ao nível do ERJ. ${ }^{14}$

${ }^{14} \mathrm{O}$ percentual de analfabetos no ERJ em 2000 era de 6,2\%. 
Quanto à formação profissional e ensino básico e médio, podemos observar, na Tabela 6, a evolução do número de escolas de nível fundamental e nível médio, nos exercícios auferidos pelo IBGE, em Campos dos Goytacazes. Percebe-se um aumento médio da ordem de $6,1 \%$ no número de estabelecimentos de Ensino Fundamental e um aumento médio da ordem de 3,8\% no número de estabelecimentos de Ensino Médio.

A atuação do município de Campos dos Goytacazes ao que respeita ao Ensino Fundamental, nível educacional de sua alçada, resultou no incremento de 20 unidades escolares (14,6\%), enquanto no Ensino Médio o município, segundo dados do IBGE, deixou de oferecer estabelecimentos de ensino.

Tabela 6 - Número de Estabelecimentos de Ensino Médio - Campos dos Goytacazes

\begin{tabular}{|c|c|c|c|c|c|c|}
\hline Nível & Alçada & 2005 & 2007 & 2009 & 2012 & 2015 \\
\hline \multirow{6}{*}{$\begin{array}{l}\text { Ensino Fundamental } \\
\qquad \text { (EF) }\end{array}$} & Municipal & 137 & 144 & 160 & 161 & 157 \\
\hline & Estadual & 96 & 80 & 55 & 51 & 51 \\
\hline & Federal & - & - & - & - & - \\
\hline & Privado & 77 & 82 & 101 & 124 & 121 \\
\hline & Total EF & 310 & 306 & 316 & 336 & 329 \\
\hline & Ideb & 2,7 & 3,2 & 3,1 & 3,3 & 3,6 \\
\hline \multirow{5}{*}{$\begin{array}{l}\text { Ensino Médio } \\
\qquad \text { (EM) }\end{array}$} & Municipal & 4 & 3 & 2 & - & - \\
\hline & Estadual & 35 & 37 & 38 & 43 & 48 \\
\hline & Federal & 1 & 1 & 2 & 2 & 2 \\
\hline & Privado & 12 & 15 & 17 & 17 & 19 \\
\hline & Total EM & 53 & 53 & 53 & 56 & 55 \\
\hline \multicolumn{2}{|c|}{ Total Geral } & 363 & 359 & 369 & 392 & 384 \\
\hline
\end{tabular}

Fonte: IBGE Cidades, 2017. Elaboração própria.

Antagonicamente a essa melhora no número de estabelecimentos de Ensino Fundamental, percebe-se o indicador Índice de Desenvolvimento da Educação Básica - Ideb - referente a 2015 com a pontuação de 3,6, posicionando Campos dos Goytacazes na 89 a posição entre os 92 municípios do ERJ e com o pior resultado entre os municípios do norte fluminense.

A análise do desenvolvimento social em Campos dos Goytacazes e municípios selecionados considera indicadores relacionados à pobreza, com base nos dados disponibilizados pelo Instituto de Pesquisa Econômica Aplicada - Ipea. A redução na taxa de pobreza no período 1991/2000 foi experimentado por todos os municípios analisados.

Os índices de pobreza em Campos dos Goytacazes são comparáveis aos índices para o conjunto do país. ${ }^{15} \mathrm{O}$ percentual de pobres de Campos dos Goytacazes para os anos analisados, contudo, é superior aos dos municípios de Macaé e Niterói. O que explicaria a não redução da pobreza no município de Campos dos Goytacazes no período analisado? As décadas de 90 e de 2000 correspondem ao período que compreende o fim do ciclo sucroalcooleiro em Campos dos Goytacazes e região e o início do ciclo baseado na indústria petrolífera. Embora no ano de 2000 se observe uma redução no índi- 
ce de pobreza da população de Campos dos Goytacazes, destaca-se que o percentual de $30,4 \%$ de pobres é consideravelmente elevado, a ponto de colocar Campos dos Goytacazes como o 69을 município no ranking de índice de pobreza no ERJ.

$\mathrm{O}$ acesso aos recursos, sejam materiais ou humanos, que propiciam a melhoria das condições de saúde da população de uma região é outro importante aspecto no contexto do desenvolvimento socioeconômico. O volume de investimentos per capita é um relevante indicador do direcionamento do esforço dos agentes públicos na busca de melhores condições de vida da população e o volume investido nos municípios no período analisado são demonstrados na Tabela 7.

Tabela 7 - Investimento per capita em saúde - dos municípios analisados - 2004 a 2014

\begin{tabular}{l|r|r|r|r|r|r|r|r|r|r|r|r|}
\hline & 2004 & 2005 & 2006 & 2007 & 2008 & 2009 & 2010 & 2011 & 2012 & 2013 & 2014 & Média \\
\hline Campos & 0,86 & 0,92 & 1,55 & 1,48 & 2,22 & 1,99 & 2,72 & 2,92 & 3,63 & 1,03 & 1,09 & 1,86 \\
Macaé & 1,66 & 1,74 & 2,48 & 2,89 & 3,53 & 3,47 & 4,41 & 5,06 & 6,48 & 3,77 & 4,53 & 3,64 \\
Niterói & 0,53 & 0,56 & 0,74 & 0,88 & 1,56 & 1,10 & 1,25 & 1,48 & 2,04 & 1,54 & 1,73 & 1,22 \\
\hline
\end{tabular}

Fonte: BRASIL, 2017b. Valores R\$ constantes - base 2014. Elaboração própria.

Verifica-se, então, que Macaé é o município que apresenta o maior nível de investimento per capita em saúde no período $2004 / 2014,{ }^{16}$ seguido de Campos dos Goytacazes e depois Niterói. Em 2013, porém, o investimento per capita na saúde em Campos dos Goytacazes caiu e se manteve, também em 2014, abaixo do investimento per capita de Niterói.

Em resumo, podemos apreciar o desenvolvimento do município de Campos utilizando o índice de Desenvolvimento Humano Municipal (IDHM), que resume os indicadores anteriores. Na Tabela 8 apresenta-se o IDHM dos municípios de Campos dos Goytacazes, Macaé e Niterói, calculados para os anos de 1991, 2000 e 2010. Todos os municípios analisados apresentaram melhora nas três mensurações realizadas. A pior performance desses índices, em comparação com o ERJ, é apresentada por Campos dos Goytacazes, seguida por Macaé, os dois maiores receptores de royalties e participações especiais.

Tabela 8 - Índice de Desenvolvimento Humano Municipal - IDHM

\begin{tabular}{llll}
\hline \multicolumn{1}{c}{ Município } & 1991 & 2000 & 2010 \\
\hline Campos dos Goytacazes & 0,505 & 0,618 & 0,716 \\
\hline Macaé & 0,534 & 0,665 & 0,764 \\
\hline Niterói & 0,681 & 0,771 & 0,837 \\
\hline ERJ (IDH) & 0,639 & 0,716 & 0,799 \\
\hline
\end{tabular}

Fonte: IBGE, 2017 - PNUD, 2010. Elaboração própria.

A situação de Campos dos Goytacazes frustrou a expectativa dos residentes locais sobre se tais recursos seriam utilizados de forma sistemática em infraestrutura urbana e melhoria das condições humanas no município. Isto mais uma vez nos leva a considerar

\footnotetext{
${ }^{16} \mathrm{O}$ órgão fomentador (DataSus) da informação dos investimentos orçamentários em saúde somente disponibiliza dados a partir de 2004.
} 
o postulado por Sachs e Warner (1995) no que diz respeito à má utilização dos recursos financeiros oriundos da extração do recurso mineral abundante, decorrente de descuido ou improbidade do gestor público.

\section{CONSIDERAÇÕES FINAIS}

Campos dos Goytacazes ressurge no cenário econômico nacional nos anos 90 inserida na região da Bacia de Campos - maior produtora de petróleo do Brasil - e passa a se beneficiar de um vigoroso ciclo expansivo, impulsionado por bilionários investimentos realizados pela indústria offshore de P\&G. A partir de 1999, diferentemente dos dois períodos expansivos que o precederam, o recente ciclo do P\&G tem seu dinamismo pautado em vultosos investimentos em infraestrutura produtiva para a exploração, pesquisa e desenvolvimento de $P \& G$ no mar.

Esse novo cenário reacende a possibilidade de superação do subdesenvolvimento no município de Campos dos Goytacazes, devido às externalidades decorrentes dos referidos investimentos, que se somam ao incremento da capacidade financeira do município para a realização de gastos públicos, posto que o município no período foi o maior receptor de royalties e participações especiais do Brasil. Os recursos de royalties e participações especiais auferidos por Campos dos Goytacazes nos anos 2000, por exemplo, passaram a representar mais da metade de suas receitas orçamentárias, o que revela a importância das atividades petrolíferas não somente para Campos dos Goytacazes, mas para os demais municípios que integram a Bacia de Campos no norte/noroeste fluminense, que também recebem royalties.

O recorte analítico de Sachs e Warner (1995), por sua vez, considera que regiões ricas em recursos naturais tendem a priorizar setores econômicos relacionados à extração do recurso natural abundante, em detrimento da indústria de transformação, assim como propõe que exista uma relação inversa entre a indústria extrativa mineral e atividade da indústria de transformação. Conforme já exposto, essas proposições não são passíveis de detecção devido à limitação das informações fornecidas pelos órgãos estatísticos.

Os condicionantes estruturais do subdesenvolvimento estão bastante enraizados em Campos dos Goytacazes, pois mesmo com a significativa geração de riqueza proveniente das atividades de exploração e produção de $P \& G$, o município não se mostrou capaz de gerar condições locais que viabilizassem de forma sustentada o desenvolvimento socioeconômico da região.

As evidências empíricas demonstram que a produção de riquezas, per se, têm sido insuficientes para garantir os avanços desejados no desenvolvimento local, especialmente no que se relaciona ao desenvolvimento social, como referido na seção anterior. Então, se o capital físico e monetário não se colocam mais como restrição ao desenvolvimento local - cuja escassez é definida pela literatura especializada como uma das principais causas do subdesenvolvimento - como explicar a letargia econômica e social deste município? 
Em uma perspectiva furtadiana, considera-se que grande parte da resposta ao questionamento anterior encontra-se na histórica inserção subordinada de Campos dos Goytacazes, não somente ao Rio de Janeiro - que exerceu o papel de centro econômico e político do país por séculos - mas também na sua inserção na divisão internacional do trabalho na produção e exportação de açúcar para o exterior, entre os séculos 17 e 19.

A produção de produtos primários (especialmente açúcar e álcool) e o sistemático emprego de mão de obra escrava durante séculos levou à formação de instituições e de uma cultura com lógicas muito peculiares e perversas em Campos dos Goytacazes. A cultura enraizada na localidade desfavorece o empreendedorismo, especialmente em atividades industriais. Por outro lado, as históricas relações clientelistas no âmbito das instituições locais, especialmente no governo municipal, pouco mudaram. Estas forças sobrepõem-se aos estímulos positivos autônomos do desenvolvimento produzidos pelo ciclo virtuoso do P\&G.

Assim, características pertinentes a uma economia subdesenvolvida, tais como: contexto histórico derivado de uma atividade agrícola extrativista, baixa heterogeneidade produtiva, concentração de renda em uma elite vinculada às atividades extrativistas primárias, incapacidade empresarial e ação inadequada do gestor público, fragilizam, do ponto de vista estrutural e institucional, a internalização dos fatores produzidos pelo atual ciclo expansivo em favor do crescimento e do desenvolvimento.

Ainda acerca da questão institucional, a abordagem de Sachs e Warner (1995) lançam luz no que respeita à deterioração do já fragilizado arcabouço institucional de Campos dos Goytacazes. Como visto, segundo estes autores, a produção de recursos abundantes tende a criar problemas institucionais de ordens diversas, que comprometem o crescimento e o desenvolvimento socioeconômico. Entre as instituições afetadas os autores destacam duas: as instituições de ensino e o governo. Quanto às primeiras, considerável parte da formação local passa a ser direcionada para atender direta e indiretamente à demanda dos setores ligados à produção do recurso abundante (P\&G), em detrimento de atividades ligadas à indústria de transformação. Como o recurso natural é finito, a concentração da produção nesta atividade compromete o desenvolvimento sustentável da localidade/região.

A inquietude perante a depreciação ainda maior desse cenário de subdesenvolvimento, devido ao não aproveitamento das oportunidades que se definiram recentemente para Campos dos Goytacazes e região, por meio da indústria de $P \& G$, agrava-se ainda mais por conta dos cortes nos investimentos produtivos em $P \& G$ derivados da crise que assolou nos últimos tempos a economia global e a Petrobras, promovendo a escassez das rendas petrolíferas.

Cabe enfatizar que a análise do desenvolvimento socioeconômico do município de Campos dos Goytacazes, no contexto do recente e expressivo ciclo expansivo do P\&G, traz aspectos positivos e negativos que merecem ser investigados por novos estudos, com vistas à superação de seu subdesenvolvimento. 
Por fim vale ressaltar a já iniciada produção nas jazidas de P\&G na camada pré-sal na Bacia de Campos, assim como os investimentos fronteiriços ao município, como a construção e funcionamento do complexo industrial-portuário do Açu e da construção do Complexo de Barra do Furado, como possibilidades de se viabilizar o crescimento econômico produtivo e posterior desenvolvimento socioeconômico do município.

Com efeito, o ciclo do petróleo e o pacote de investimentos no norte fluminense que este vem estimulando constituem-se em importantes objetos de análise, em particular no que diz respeito à identificação de elementos que remetam à superação dos condicionantes estruturais do subdesenvolvimento não apenas em Campos dos Goytacazes, mas também no norte fluminense, por conta da magnitude produtiva e tecnológica inerentes aos investimentos supracitados.

\section{REFERÊNCIAS}

BRASIL. Lei $n$ o 9.478, de 6 de agosto de 1997. Brasília. Disponível em: http://www.planalto.gov.br/ccivil_03/leis/L9478.htm. Acesso em: 16 jul. 2017.

BRASIL. Cadastro Geral de Empregados e Desempregados (Caged). Base de dados on-line. 2017a. Disponível em: https://mte.gov.br/portalcaged. Acesso em: 20 jun. 2017.

BRASIL. Ministério da Saúde. Sistema de Informações sobre Orçamentos Públicos em Saúde (Siops). Disponível em: http://siops.datasus.gov.br. Acesso em: 22 jul. 2017b.

BRASIL. Relação Anual de Informações Sociais (Rais). Ministério do Trabalho. Disponível em: portal.mte. gov.br/rais/estatisticas.htm. Acesso em: 15 jul. 2017c.

CAVALIERI, H.; TORRES, R.; HASENCLEVER, L. Mudança estrutural e especialização produtiva: potenciais e desafios para o Estado do Rio de Janeiro. In: ALTEC - ASSOCIAÇÃO LATINO-AMERICANA DE TECNOLOGIA, 2013. Portugal. Anais[...] Portugal, 2013.

CRUZ, José Luiz Vianna da. Modernização produtiva, crescimento econômico e pobreza no Norte Fluminense (1970-2000). In: PESSANHA, Roberto Moraes; SILVA NETO, Romeu (org.).Economia e desenvolvimento no norte fluminense: da cana-de-açúcar aos royalties do petróleo. Campos dos Goytacazes, RJ: WTC Editora, 2004. p. 77-117.

CUNHA, A. L. L. Planejamento e gestão da assistência social no município de Campos dos Goytacazes: 2005-2008. 2009, 127 f. Dissertação (Mestrado em Planejamento Regional e Gestão de Cidades) - Ucam, Campos dos Goytacazes, RJ, 2009.

FURTADO, Celso. Cadernos do Desenvolvimento, n. 1. 2006. Disponível em: http://www.centrocelsofurtado.org.br. Acesso em: 22 jun. 2017.

FURTADO, Celso. Desenvolvimento e subdesenvolvimento. 5. ed. Rio de Janeiro: Contraponto Editora, 2009. 34 p.

HASENCLEVER, Lia; FILHO, Edson Terra; PIQUET, Rosélia Perissé da Silva. Distribuição territorial das ocupações geradas pela atividade de petróleo e gás (p\&g) e suas qualificações no Brasil, 2003-13. Revista Brasileira de Gestão e Desenvolvimento Regional, Taubaté, SP, v. 13, n. 3, p. 223-251, set./dez. 2017. Bimestral. HIRSCHMAN, Albert O. Estratégia do desenvolvimento econômico. Rio de Janeiro: Fundo de Cultura, 1961. $322 \mathrm{p}$.

IBGE. Instituto Brasileiro de Geografia e Estatística. Sidra: banco de dados. Disponível em: http://www. sidra.ibge.gov.br. Acesso em: 22 jun. 2017.

IPEA. Instituto de Pesquisa Econômica Aplicada. Ipeadata. Disponível em: http://www.ipeadata.gov.br. Acesso em: 22 jun. 2017.

KEYNES, John Maynard. A teoria geral do emprego do juro e da moeda. São Paulo: Nova Cultural, 1996. (Coleção: Os Economistas).

MARSHALL, Alfred. Princípios de economia: tratado introdutório. São Paulo, SP: Nova Cultural, 1996. 368 p. (Coleção Os Economistas).

MYRDAL, Gunnar. Economic theory and under-developed regions. 2. ed. London: Iseb. Ministério da Educação e Cultura, 1957. 208 p.

NURKSE, Ragnar. Problemas de formação de capital em países subdesenvolvidos. Rio de Janeiro: Civilização Brasileira, 1957.

PNUD. Programa das Nações Unidas para o Desenvolvimento. 2010. 
RAIS. Relação Anual de Informações Sociais. Critérios de geração de base de dados. 2007.

ROSENDO, Roberto Cezar; CARVALHO, Ailton Mota de. Formação econômica da Região Norte Fluminense. In: PESSANHA, Roberto Moraes; SILVA NETO, Romeu e (org.). Economia e Desenvolvimento no Norte Fluminense: da cana-de-açúcar aos royalties do petróleo. Campos dos Goytacazes: WTC, 2004. p. 27-73. Cap. 1.

SACHS, Jeffrey D.; WARNER, Andrew M. Natural Resource Abundance and Economic Growth. Cambridge: National Bureau Of Economic Research, 1995. Disponível em: http://www.nber.org/papers/w5398.pdf. Acesso em: 3 jul. 2017.

SEN, A. K. Desenvolvimento com liberdade. São Paulo: Companhia das Letras, 2000. 